\title{
Laser assisted synthesis of carbon nanoparticles with controlled viscosities for printing applications
}

\author{
K. Bagga ${ }^{\text {a,b,c }}$, R. McCann ${ }^{\text {a,b,c,d }}$, M. Wang ${ }^{\text {a,b,c }}$, A. Stalcup ${ }^{\text {b }}$, M. Vázquez ${ }^{\text {a,b }}$, D. Brabazon ${ }^{\text {a,b,c,d }}$ \\ ${ }^{a}$ Advanced Processing Technology Research Centre, Dublin City University, Ireland \\ ${ }^{\mathrm{b}}$ Irish Separation Science Cluster, Dublin City University, Ireland \\ ${ }^{\mathrm{c} S c h o o l}$ of Mechanical \& Manufacturing Engineering, Dublin City University, Ireland \\ ${ }^{\mathrm{d}}$ National Centre for Plasma Science \& Technology (NCPST), Dublin City University, Ireland
}

\begin{abstract}
High-quality carbon nanoparticles with controlled viscosity and high aqueous stability were prepared by liquid-phase laser ablation of a graphite target in deionized water. The size distribution was found to vary from $5 \mathrm{~nm}$ to $50 \mathrm{~nm}$ with mean size of $18 \mathrm{~nm}$, in the absence of any reducing chemical reagents. Efficient generation of short chain polyynes was recorded for high laser repetition rates. Homogeneous and stable nanoparticle suspensions with viscosities ranging from 0.89 to $12 \mathrm{mPa}$.s were obtained by suspending the nanoparticles in different solvent mixtures such as glycerol-water and isopropanol-water. Optical properties were investigated by absorption and photoluminescence spectroscopy. Raman spectroscopy confirmed graphitic-like structure of nanoparticles and the surface chemistry was revealed by Fouriertransform infrared spectroscopy demonstrating sufficient electrostatic stabilization to avoid particle coagulation or flocculation. This paper present an exciting alternative method to engineer carbon nanoparticles and their potential use as a ligand-free nano-ink for ink jet printing (jetting) applications.
\end{abstract}

\section{Keywords}

Carbon nanoparticles, Laser ablation in liquid, High frequency laser, Polyynes, Viscosity, Nano-ink, Printing applications, Absorption spectroscopy, Transmission electronic microscopy

\section{Introduction}

In the last decade, rapid progress has been made in the synthesis of a variety of carbon-based nanomaterials for novel applications in diverse areas such as electronics, sensors, and energy. Specifically, carbon nanoparticles (CNPs) have emerged as a new class of carbon-based nanomaterial with several desirable photophysical properties, chemical inertness, stability, high (aqueous) dispersity [1]. The superior biological properties of CNPs, such as low toxicity and biocompatibility, has significantly contributed in replacing traditional semiconductor quantum dots by CNPs in bioimaging, biosensor and biomolecule/drug delivery applications [2,3]. Exceptional optical and electronic properties of CNPs, include 
their ability for photoinduced electron transfer, photoluminescence and exceptional conductivity due to their dual role as electron donors and acceptors. CNPs can therefore be integrated within existing technologies for creating nanoscale optoelectronic devices [4] and nanosensors [5]. To date, a variety of techniques have been developed to prepare CNPs. In general, these techniques can be classified into top-down and bottom-up approaches. Topdown strategies include electrochemical synthesis [6], laser ablation [7], and arc discharge [8]. Bottom-up strategies include ultrasonic methods [9], microwave assisted synthesis [10], and hydrothermal treatment [11].

Specific technological applications require particular surface activity of the nanomaterials, as for instance in the ink-jet printing of nanomaterials for surface coating of electronic/photonic devices [12]. In this case, it is highly desirable to obtain nanoparticles without any precursor residues and stabilizing ligands. The molecules (ligands) on the surface of a nanoparticle decrease its activity which in turn decreases its electrical conductivity. Hence this requirement has led to expensive follow-up treatments and cleaning steps after nanoparticle synthesis, such as the calcination of catalyst supports or the filtration of nanomaterials [13].

Alternatively, Pulsed Laser Ablation in Liquids (PLAL) has emerged as a versatile technique to fabricate a variety of nanomaterials [14]. As a general strategy, an intense laser beam is irradiated on the surface of a solid target resulting in the generation of a plasma plume at the liquid-solid interface. This results in the simultaneous formation and ejection of nanoclusters of the target material into the confining medium, thus leading to the formation of ultrapure colloidal nanoparticles in solution [15]. By changing the laser parameters, target material and liquid media, the size, morphology and surface chemistry of the nanoparticles can be precisely controlled [16,17]. Several studies have been published reporting PLAL as an effective method for the generation of interesting carbon-based nanomaterials including nanoparticles [18] and polyynes [19]. Polyynes are of significance in materials science due to their one-dimensional electronic structures, size-dependent band gaps [20] and nonlinear optical properties [21].

In this work, we exploit this unique technique (i.e. PLAL) to generate nanoparticles with novel functionalities to be used as nano-inks in ink-jet printing (jetting) technology. Over the years, ink-jet printing techniques have become attractive alternatives to conventional photolithography or screen-printing for patterning various functional materials such as organic light emitting diodes (OLED), printed scaffolds for growth of living tissues, and building 3D objects [22]. An important advantage of nanoparticle based inks is the large surface/volume ratio that these particles offer. This can allow low annealing temperature, short process time, high conductivity [23] and high density functionalisation to obtain a wide variety of surface chemistries for different ink-jet printing applications [24].

The present work focuses on the use of laser assisted method, PLAL, for preparation of highquality carbon nanoparticles based colloids with controlled viscosity. To the best of our knowledge, this is the first time demonstration of laser generated carbon nanoparticles, towards their application as nano-inks in jetting technology. Optical properties were investigated by absorption and photoluminescence spectroscopy. Raman and Fouriertransform infrared (FTIR) spectroscopy were performed to reveal the chemical structure of 
the nanoparticles. Viscosity measurements in different solvent mixtures were performed in order to optimize the viscosity of the CNP based colloids.

\section{Materials and methods}

\subsection{Synthesis}

Laser ablation experiments were carried out using a Nd:YAG laser system (WEDGE HF 1064, Bright Solutions) providing pulses centred at $1064 \mathrm{~nm}$ and with a pulse width of $700 \mathrm{ps}$ at the repetition rate set at $7 \mathrm{kHz}$ for production of CNPs and $10 \mathrm{kHz}$ for generation of polyynes. The graphite target (99.999\% pure from Sigma Aldrich) in cylindrical form with a diameter of $6 \mathrm{~mm}$ and height of $8 \mathrm{~mm}$ was placed on the bottom of a glass cuvette (dimension $101050 \mathrm{~mm}$ ). The cuvette was filled with $2 \mathrm{~mL}$ deionised water (DI water) which corresponded to $1 \mathrm{~cm}$ of liquid above the surface of the target. The target was mechanically polished, and then washed with deionised water several times to remove any impurities from the surface. The laser beam was focused onto the target material using a lens with a focal length of $30 \mathrm{~cm}$. During all the experiments, the graphite target was placed in the focal plane of laser beam. A 2-dimensional scanning galvanometer (SS-12, Raylase) was used to scan the laser beam across the top of the graphite target in a circular pattern, at a scan rate of 1.2 $\mathrm{mm} / \mathrm{s}$. The laser fluence was measured experimentally using a 30A-P-17 OPHIR power meter. The laser ablation parameters are defined as follows, unless indicated otherwise. For the production of CNPs, the ablation was carried out at an energy density ranging from 0.02 $\mathrm{J} . \mathrm{cm}^{2}$ to $0.71 \mathrm{~J} . \mathrm{cm}^{2}$ for a $30 \mathrm{~min}$ irradiation time, and for the generation of polyynes the laser

fluence was fixed at $0.40 \mathrm{~J} . \mathrm{cm}^{2}$ for a $10 \mathrm{~min}$ irradiation time. Additionally, the effect of ablation time on production of nanoparticles was also investigated at a fixed laser fluence. The formation of carbon nanostructures could be estimated by the slight change of the colour (from transparent to varying tones of grey) of the liquid during ablation.

However it should be noted that changes in the colour of the colloidal solution were only recorded for high levels of fluence. The sample preparation for each characterization measurement was performed one day after preparation of the colloids.

\subsection{Characterization}

Optical absorption spectra were recorded in a quartz cuvette (10 $\mathrm{mm}$ pathlength, Helma) with Varian Cary 50 UV-Vis spectrophotometer. The scan range was 200-1200 nm with a $600 \mathrm{~nm} / \mathrm{min}$ scan rate. Photoluminescence of the colloidal solution was measured using a Jasco FP-8500 fluorescence spectrometer. All the optical spectra were corrected for water absorption, by subtracting the contribution of water from the recorded spectrum.

Transmission Electron Microscopy (TEM) was performed with a FEI titan instrument, operating at $300 \mathrm{kV}$, equipped with a Field Emission Gun (FEG), spherical aberration corrector system (Cs-corrector) of the objective lens. The samples were prepared by drop 
casting the colloidal solution onto carbon coated 300 mesh copper grid and left to evaporate at room temperature.

The nanoparticles were sonicated in distilled water for $20 \mathrm{~min}$ and then their stability in water was studied in a dynamic light scattering (DLS) experiment using a Zetasizer Nano ZS ( Malvern Instruments Ltd). Micro-probe Raman measurements were performed with Jobin-Yvon Horiba LabRam HR800 system at $20 \mathrm{~mW}$ and $1 \mathrm{~lm}^{2}$ spot size (with Ar+ 488 $\mathrm{nm}$ air cooled laser, accumulation time $=20 \mathrm{~s}$ ) in a backscattering configuration with resolution of about $1.1 \mathrm{~cm}^{1}$. Sample preparation for Raman measurements was done by depositing colloidal CNP solution over the substrate by drop casting method. The excess of liquid was then left to evaporate at room temperature leading to the formation of a "coffee ring". This technique is commonly accepted as the property of the material in the coffee ring remains the same as in the original sample [25]. Various measurements were performed at different position on the coffee ring. Fourier Transform Infrared spectroscopy (FTIR) was performed on a Perkin-Elemer Spectrum 100 FTIR spectrometer. The data was acquired in transmission and ATR imaging modes over the spectral range the $600-4000$ $\mathrm{cm}^{1}$. Viscosities of the CNP suspensions were measured with an Anton Paar MCR 301 Rheometer system with maximum torque capability of $200 \mathrm{mNm}$, resolution of $0.1 \mathrm{nNm}$, and a maximum angular velocity of $628 \mathrm{rad} / \mathrm{s}$.

\section{Results and discussion}

\subsection{TEM characterization}

TEM characterization was carried out to obtain information about the morphology and size distributions in the colloidal solutions produced by laser ablation of the graphite target in deionized water.

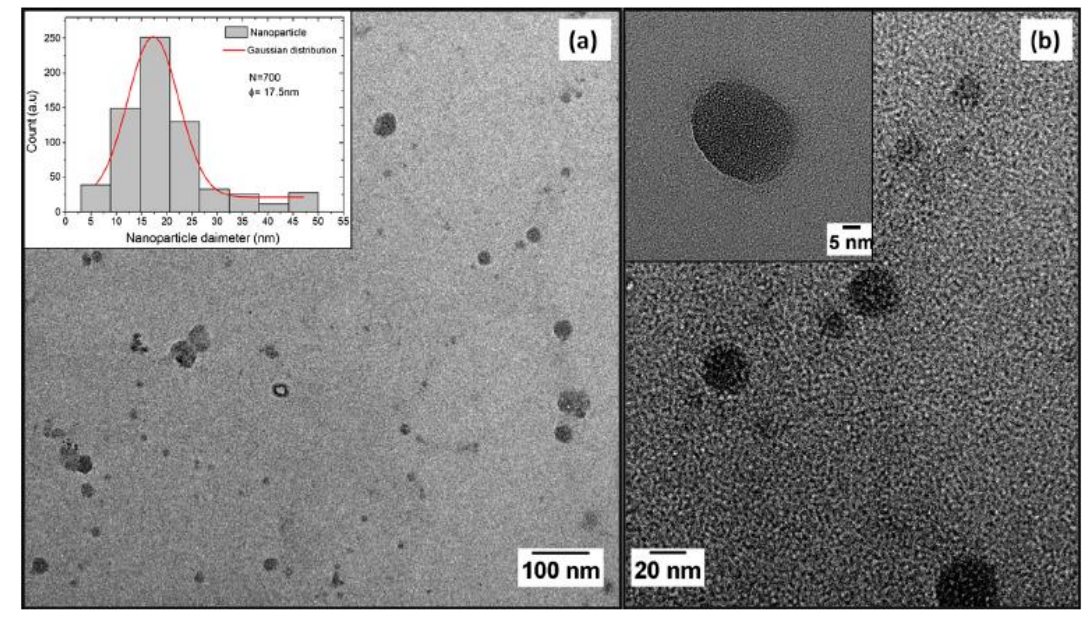

Fig. 1. TEM analyses of the CNPs obtained by picosecond laser ablation of graphite target in DI water at energy density $0.40 \mathrm{~J} . \mathrm{cm}^{-2}$ at different magnifications. The scale bar for the TEM images is (a) $100 \mathrm{~nm}$ (b) $20 \mathrm{~nm}$ and inset of (b) is $5 \mathrm{~nm}$. The mean and size distribution of the CNPs are reported in the inset of (a).A particle size distribution with mean NP diameter of $18 \mathrm{~nm}$ was obtained within almost all the CNPS colloidal solutions with size dispersion ranging from $5 \mathrm{~nm}$ to $50 \mathrm{~nm}$. 
Fig. 1 shows TEM images of NPs obtained at $0.40 \mathrm{~J} . \mathrm{cm}^{2}$ laser irradiance for $5 \mathrm{~min}$. Isolated and uniformly distributed CNPs could be observed at low (Fig 1a) and high magnification (Fig 1b).

\subsection{Optical measurements}

CNPs solutions were produced by laser ablation of a graphite target in deionized water, using picosecond laser pulses emitting at $1064 \mathrm{~nm}$ at $7 \mathrm{kHz}$, by varying the laser fluence $0.02,0.40,0.50,0.60$ and $0.70 \mathrm{~J} . \mathrm{cm}^{2}$ for a fixed irradiation time of $30 \mathrm{~min}$. Fig. 2 shows the UV-visible absorption measurements of the obtained colloid solutions. The spectra of each colloidal solution consisted of a broad continuous band between 200 and $500 \mathrm{~nm}$ and a distinctive shoulder at around $260 \mathrm{~nm}$, except for the solution obtained at lowest energy density. A strong increase in the UV absorption band was recorded from increased energy density indicating that the production of NP population is in the size range of around 5-10 $\mathrm{nm}$ which is agreement with the TEM analysis.

In addition, a strong background absorption at wavelength up to about $500 \mathrm{~nm}$ could be observed. The occurrence of this typical absorbance band and background extinction has been reported previously for CNPs [26]. The exact assignment of the peaks in the absorption spectra is still not known, however the UV absorption band at around $230 \mathrm{~nm}$ is attributed to $\mathrm{n}$ ?p* of C@C [27], and the shoulder at $260300 \mathrm{~nm}$ corresponds to p?p ${ }^{*}$ transition of the C@O bonds [28,29]. Carboxyl groups may form on the surface of CNPs as they are produced during the plasma nucleation phase of the laser ablation process in DI water, while C@C could be produced directly from the graphitic core. As previously reported [7], when excited at $360 \mathrm{~nm}$, the CNPs showed strong blue- green photoluminescence (PL) centred at approximately $430 \mathrm{~nm}$ (inset Fig. 2a). The luminescence from CNPs demonstrated that there was radiative recombination of excitons at the particle surface during plasma assisted generation [30].

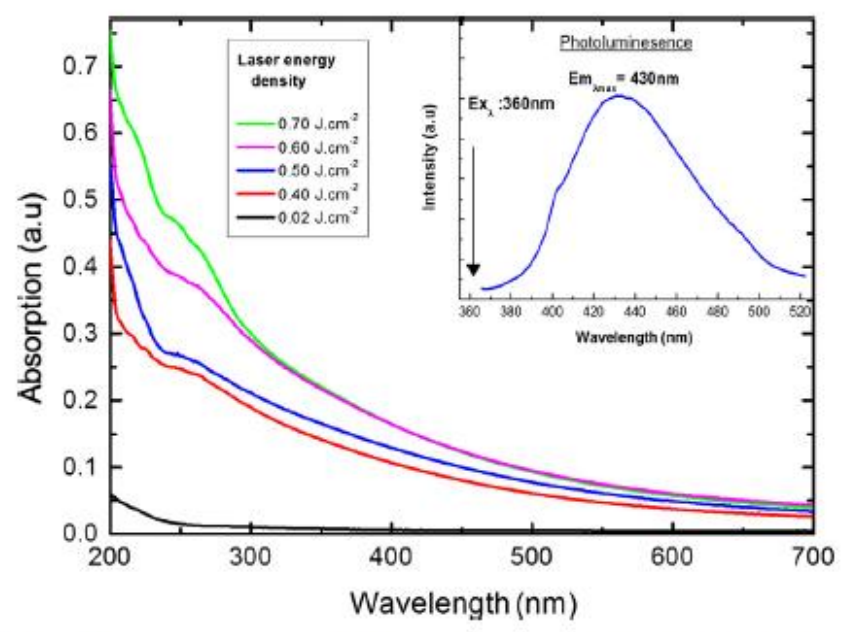

Fig. 2. (a) Absorption spectra of the CNPs produced via picosecond laser ablation of a graphite target in deionised water at different laser fluence (indicated) for a fixed irradiation time of $30 \mathrm{~min}$ and (b) photoluminescence spectra of the colloid obtained at $0.40 \mathrm{J.cm} \mathrm{cm}^{-2}$ (excitation wavelength: $360 \mathrm{~nm}$ ). 
Additionally, the functional groups present on the surface of the CNPs might have also been responsible for the PL emission [7].

Apart from parameters such as pulse energy, repetition rate and level of the liquid above the target [31], another important parameter in the PLAL technique which directly influences the productivity/yield of NP material in the colloids is the irradiation time [32]. Fig. 3(a) shows UV-Vis spectra of the colloidal solutions obtained after 1, 2, 5 and 10 min of ablation of graphite in DI water at $0.90 \mathrm{~J} . \mathrm{cm}^{2}$. A significant increase in the intensity of the characteristic absorption peak is observed with increased laser irradiation time which is attributed to an increase in the amount of nanoparticles in the colloids. The colour of the colloidal solution changed from light to dark grey with increasing ablation time. However, it should be noted that there was no shift in the absorption maximum $\left(\lambda_{\max }\right)$ with increasing ablation time, indicating the particle size remained constant with increasing irradiation time. This could be explained, considering that the produced CNPs with mean size around $18 \mathrm{~nm}$ do not absorb or interact with $1064 \mathrm{~nm}$ laser pulses and therefore no photo fragmentation takes place over time [19].

Fig. 3(b) shows the carbon ablated mass in the colloidal solution as the function of ablation time at high laser fluence $\left(0.90 \mathrm{~J}_{\mathrm{cm}} \mathrm{cm}^{-2}\right)$. A linear increase of the ablated mass as function of ablation time was recorded. This value varied from $1.3 \mathrm{mg}$ to $4.6 \mathrm{mg}$ as the ablation time was increased from 60 to $300 \mathrm{~min}$, indicating a productivity rate of $0.02 \mathrm{mg} / \mathrm{min}$, which is highly competitive with chemical synthesis methods. It should be noted that the mass ablated was estimated by evaluation of the target mass lost after laser processing. In case of a highly monodisperse suspension ( size dispersion $<5 \%$, which is not our case) this value could be utilized to estimate the number of NPs in the colloid [17] .

Laser ablation in liquid has been demonstrated as a highly simple method to produce high concentration of polyynes [33], particularly with the $1064 \mathrm{~nm}$ laser wavelength. However, not much work has been reported of polyynes production at high pulse repetition frequency. Fig. 4 shows the UV-Vis spectra of the polyynes solutions prepared by laser ablation of graphite in deionized water at $10 \mathrm{kHz}(0.4-0.95 \mathrm{~J} . \mathrm{cm} 2)$.
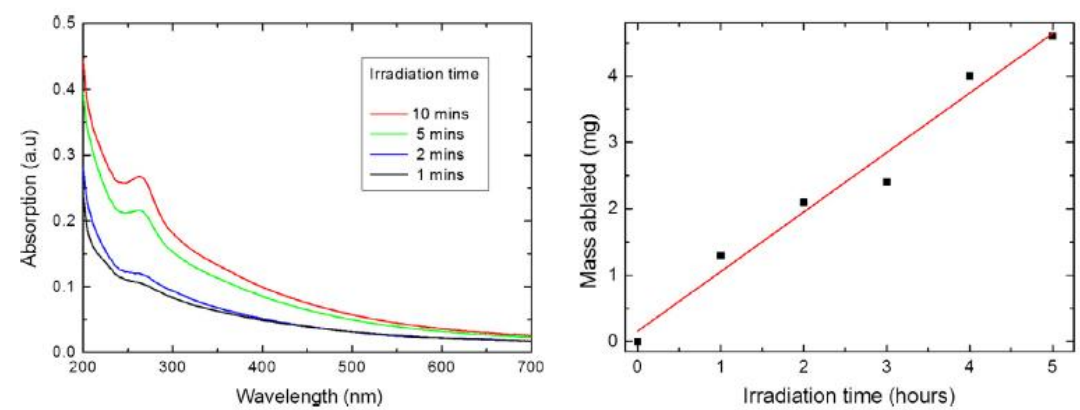

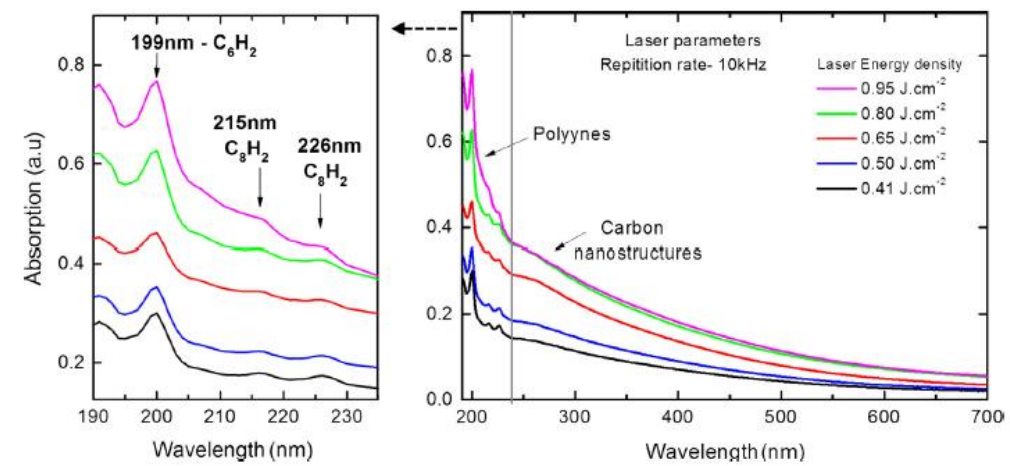

Fig 4. Typical UV absorption spectrum of a polyyne solution formed by laser ablation of a graphite target in deionized water at $10 \mathrm{kHz}$ with varying fluence from 0.4 to Fig 4. Typic

Characteristic absorption peaks of polyynes were evident in the wavelength region of 190$250 \mathrm{~nm}$, assigned according to the number of carbon atoms in the polyynes. For example 199 $\mathrm{nm}$ reflects the presence of $\mathrm{C}_{6} \mathrm{H}_{2}$, while those at $215 \mathrm{~nm}$ and $226 \mathrm{~nm}$ belong to $\mathrm{C}_{8} \mathrm{H}_{2}$ [9]. As seen in Fig 4, the peak intensities of $\mathrm{C}_{6} \mathrm{H}_{2}$ were more pronounced than those of $\mathrm{C}_{8} \mathrm{H}_{2}$ for all our samples, indicating more favourable generation of shorter chain polyynes $\left(\mathrm{C}_{6} \mathrm{H}_{2}\right)$ at higher laser repetition rate. During liquid phase laser ablation the high energy photochemical ablation process can overcome the high energy polyynes moiety activation barriers in a short period of time and thereby results in mainly short-length polyynes $(n<10)$ [34].

\subsection{Surface analysis: Raman and FTIR spectroscopy}

Raman spectroscopy has been widely used to examine crystallinity and reveal the defects in carbon structures by identifying even slight changes in orientation of CAC bonds [35]. Fig. 5 represents Raman spectrum of laser generated CNPs, dominated by the two features typically observed for graphite-based materials: $1365 \mathrm{~cm}^{1}$ (D band - disordered carbon band related to the presence of $\mathrm{sp} 3$ defects) and $1570 \mathrm{~cm}^{1}$ (G band - graphitic carbon band related to in-plane vibration of $\mathrm{sp} 2$ carbon). The D-band corresponds to the defects and disordered in the carbon nanostructures, and the G-band is attributed to the well-graphitized carbon. Hence the relative intensity ratio of the disordered $\mathrm{D}$ band and the crystalline $\mathrm{G}$ band (ID/IG) is a measure of the degree of disorder and allows comparing the structural order between crystalline and amorphous graphitic systems.

It is worth mentioning that $\mathrm{I}_{\mathrm{D}} / \mathrm{I}_{\mathrm{G}}$ values vary significantly depending on the synthesis method. The $\mathrm{I}_{\mathrm{D}} / \mathrm{I}_{\mathrm{G}}$ for the CNPs obtained via PLAL was around 0.90, indicating that they have a similar graphitic-like structure [36].

FTIR analysis (Fig. 6) shows strong absorption intensities recorded for the OAH stretching at around $3200-3500 \mathrm{~cm}^{1}$ which contributed to the hydrophilicity and stability of CNPs in the aqueous systems. The stability of NPs solution is known to be directly linked to chemical nature of the NPs surface. This is also confirmed by complementary zeta potential values of CNPs, ranging from 21 to $25 \mathrm{mV}$, revealing a sufficient electrostatic stabilization of particles. 


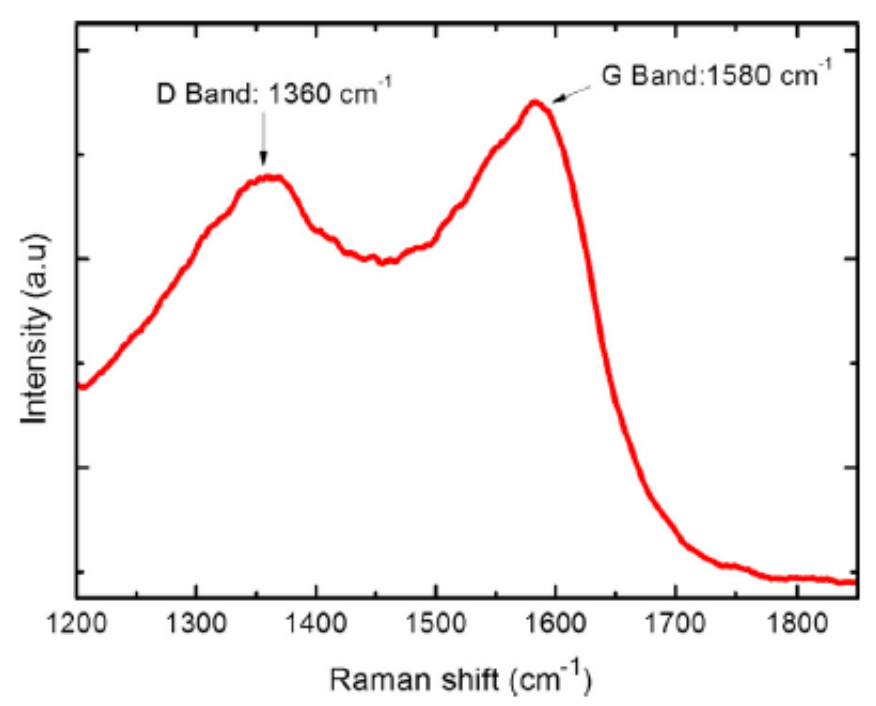

Fig. 5. Raman analysis of the CNPs obtained at an ablation fluence of $0.40 \mathrm{~J} \cdot \mathrm{cm}^{-2}$.

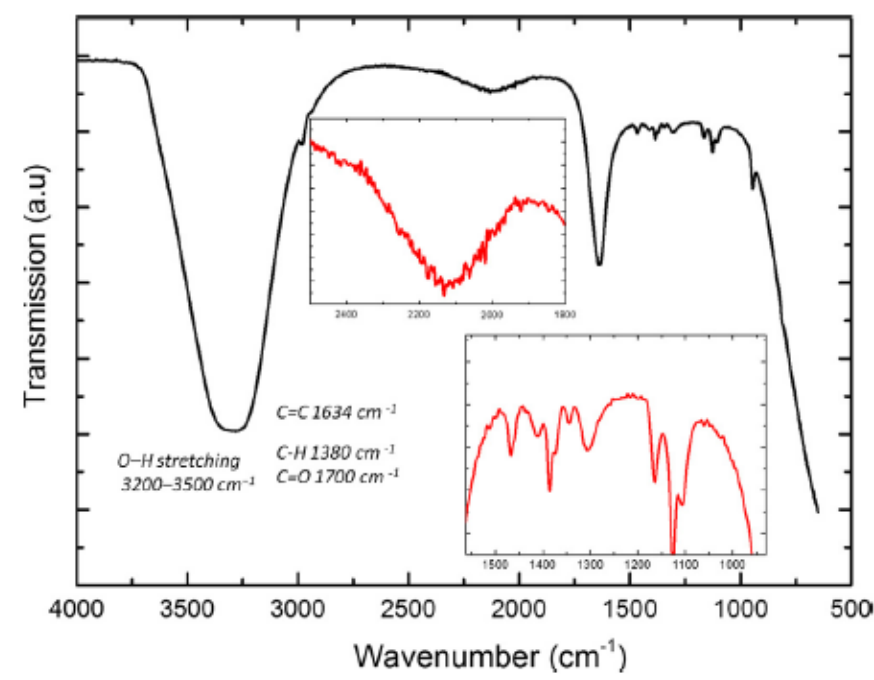

Fig. 6. Fourier-transform infrared microscopy analysis of the CNPs obtained at an energy density of $0.40 \mathrm{~J} \cdot \mathrm{cm}^{-2}$.

Additionally, other functional groups associated with the surface of CNPs were present, e.g. CAH at $1380 \mathrm{~cm}^{1}$ and $\mathrm{C} @ \mathrm{O}$ at $1700 \mathrm{~cm}^{1}$. An overtone at $1648 \mathrm{~cm}^{1}$ is due to AC@CA stretching. Presence of such functional groups could be utilized for the surface functionalization of CNPs containing $\mathrm{ACH}_{3}$ and $\mathrm{AOH}$ as linkers for molecules.

\subsection{Viscosity measurements}

A primary obstacle for the use of nanoparticles in ink-jet printing, is the presence of ligands, which hinder efficient charge transport between the particles in electronic devices 
[37]. The above described optical and zeta potential measurements results revealed the generation of stable ligand-free CNP suspension.

These bare NPs could be used for the production of nanofluid ink for ink jet printing applications. Fluid properties of the ink, such as the viscosity, density, and surface tension of the liquid, play an important role during the printing process. The value of the ink viscosity is typically within the range of $1-20 \mathrm{mPa} . \mathrm{s}$ in order to avoid the formation of undesirable flow (excessive fluidity or printer head blockage).

In this work, the viscosity of the as-produced CNPs colloids was tuned to meet commercially used inkjet fluids by mixing CNPs colloids with different solvents. Fig. 7 shows the dynamic viscosity of CNPs in an Isopropyl Alcohol (IPA)-water mixture. The results are presented as a function of volumetric concentration of IPA in final solution. A viscosity range of 0.94$2.98 \mathrm{mPa}$.s was achieved by controlling the IPA volume concentration, with the maximum viscosity ( $2.98 \mathrm{mPa} . \mathrm{s})$ achieved at 0.7 volume fraction of IPA in water. Our results were consistent with previous results on the viscosity of IPA-water mixtures which also reported a non-linear response [38].

A number of factors, including the interaction between NP and the solvent, would lead to modification of the liquid viscosity. Additional experiments were performed to investigate the effect of varying concentrations of glycerol addition on the viscosities of the CNPs suspensions. Glycerol is a non-toxic, high viscous solvent with which wide range of viscosity values can be easily achieved by mixing water and glycerol in various proportions.

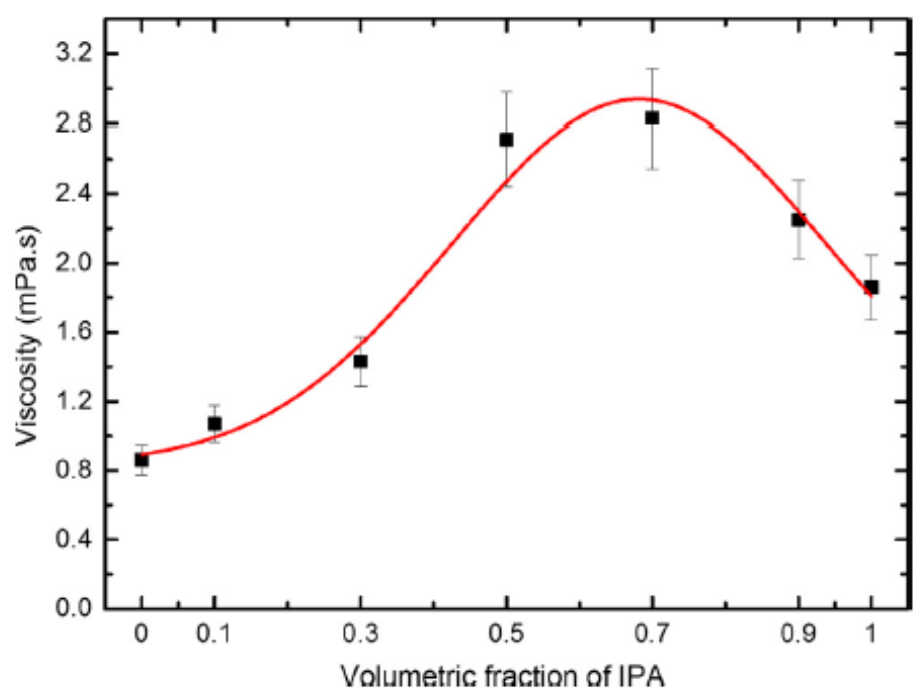

Fig. 7. Dynamic viscosity at $25^{\circ} \mathrm{C}$ for carbon nanoparticle suspended in IPA/water solutions as function of volumetric concentration of IPA. Each sample was produced from ablation lasting one hour with a laser fluence of $0.52 \mathrm{~J} . \mathrm{cm}^{-2}$.

Fig. 8 reports the dynamic viscosity at $20 \mathrm{C}$ for CNPs/water/ glycerol solutions with different glycerol concentrations (by volume). 


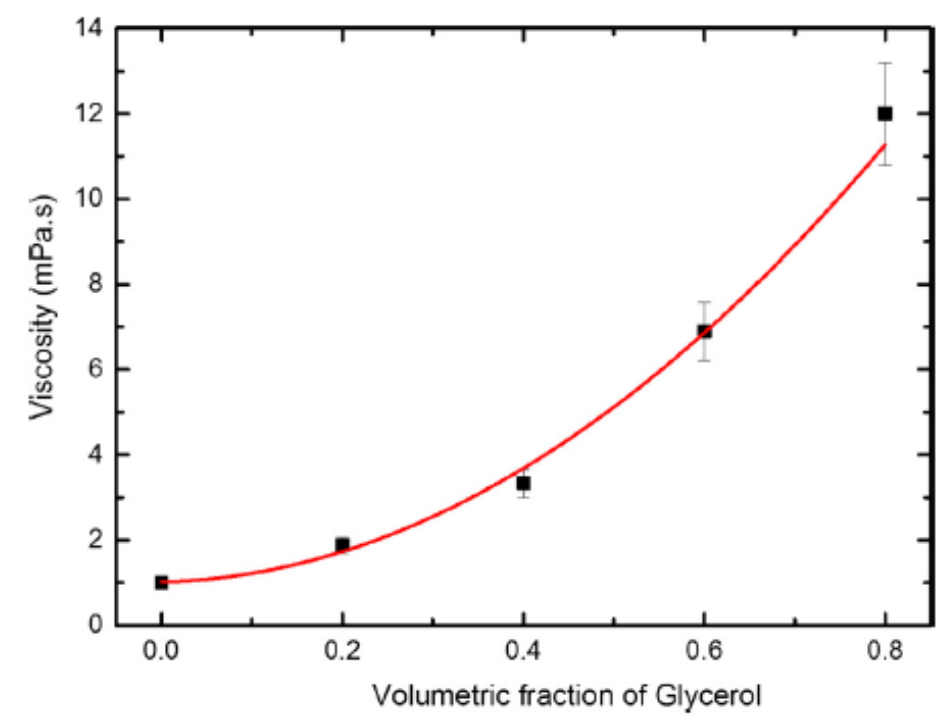

Fig. 8. Dynamic viscosity at $20^{\circ} \mathrm{C}$ for $\mathrm{CNP} /$ water/glycerol solutions with different glycerol concentrations.

The increase in viscosity from $2 \mathrm{mPa}$.s to $12 \mathrm{mPa}$.s was achieved by regulating the volume concentration of glycerol in the CNP suspensions. Maximum viscosity of $12 \mathrm{mPa}$.s was achieved at 0.8 volume fraction of glycerol in water. Lin et al. has demonstrated the feasibility of inkjet printing using a carbon nanotube suspension in water/glycerol mixture with a weight ratio of 3:1 [39]. The FTIR spectra results of the CNPs revealed hydrophilic oxygen-containing groups on the NP surface, which would promote the dispersion of the CNPs in the solvent.

\section{Conclusions}

In conclusion, this paper introduces the application of the 'green' method of Pulsed Laser Ablation in Liquids to obtain high-quality colloids of carbon nanoparticles for ink jet printing applications. With this laser assisted synthesis, not requiring added any chemical precursors or reducing agents, ligand free carbon nanoparticles of mean size around $18 \mathrm{~nm}$ and size distribution from $10 \mathrm{~nm}$ to $50 \mathrm{~nm}$ were obtained. Optical spectroscopy confirmed efficient generation of short chain polyynes at high laser repetition rates. Raman and FTIR spectroscopy revealed that the chemical structure of the nanoparticles contained similar graphitic-like structures with sufficient electrostatic stabilization to avoid particle coagulation or flocculation. Viscosity measurements in different solvent mixtures were performed in order to optimize the viscosity of the CNP based colloids. Homogeneous and stable nanoparticle suspensions with viscosity ranging from 0.89 to $12 \mathrm{mPa}$.s were obtained by suspending the nanoparticles in the different base fluids of glycol-water and isopropyl alcohol-water mixtures. This presented approach addresses the previously published report [40] highlighting the need to develop new strategies to obtain nanoparticles free from surface ligands for efficient carrier transport and their effective use in printing technologies. To the best of the authors knowledge, this is the first time demonstration of the 'single' step laser 
method to obtain ligand free carbon nanoparticles, towards their application as nano-inks within jetting systems. This technique is more environmentally friendly and less time consuming in comparison to the conventional multistep ligand removal process. The proposed combination of material and synthesis method to obtain nanoparticle based colloids has wide potential applications in electronics (e.g. printing thin film devices), biomedical devices (e.g. nanoparticle printed immunoassay for detection of biological species) and manufacturing technologies (e.g. printed sensors on textiles). High purity laser generated nanoparticle colloids with controlled viscosities may emerge as a core and affordable technique for future printing applications.

\section{Acknowledgments}

This publication has emanated from research conducted with the financial support of Science Foundation Ireland (SFI) under Grant Number 12/IA/1576. Authors would like to thank Simon Gallagher for the help in FTIR measurements.

\section{References}

[1] Y.P. Sun, B. Zhou, Y. Lin, W. Wang, K.A.S. Fernando, P. Pathak, M.J. Meziani, B.A. Harruff, X. Wang, H. Wang, P.G. Luo, H. Yang, M.E. Kose, B. Chen, L.M. Veca, S.Y. Xie, J. Am. Chem. Soc. 128 (2006) 7756, http://dx.doi.org/10.1021/ja062677d.

[2] S.N. Baker, G.A. Baker, Angew. Chem. Int. Ed. 49 (2010) 6726, http://dx.doi.org/ 10.1002/anie.200906623.

[3] Y.P. Sun, X. Wang, F. Lu, L. Cao, M.J. Meziani, P.G. Luo, L. Gu, L.M. Veca, J. Phys. Chem. C 112 (2008) 18295, http://dx.doi.org/10.1021/jp8076485.

[4] F. Wang, Y. Chen, C. Liu, D. Ma, Chem. Commun. 47 (2011) 3502, http:// dx.doi.org/10.1039/C0CC05391K.

[5] S.A. Hevia, P. Homm, F. Guzmán, H.M. Ruiz, G. Muñoz, L.S. Caballero, M. Favre,

M. Flores, Surf. Coat. Technol. 253 (2014) 161, http://dx.doi.org/10.1016/ j.surfcoat.2014.05.031.

[6] H.T. Li, X.D. He, Z.H. Kang, H. Huang, Y. Liu, J.L. Liu, S.Y. Lian, C.H.A. Tsang, X.B. Yang, S.T. Lee, Angew. Chem. Int. Ed. 49 (2010) 4430, http://dx.doi.org/ 10.1002/anie.200906154.

[7] S.L. Hu, K.Y. Niu, J. Sun, J. Yang, N.Q. Zhao, X.W. Du, J. Mater. Chem. 19 (2009) 484, http://dx.doi.org/10.1039/B812943F.

[8] X.Y. Xu, R. Ray, Y.L. Gu, H.J. Ploehn, L. Gearheart, K. Raker, W.A. Scrivens, J. Am. Chem. Soc. 126 (2004) 12736, http://dx.doi.org/10.1021/ja040082h.

[9] H.T. Li, X.D. He, Y. Liu, H. Huang, S.Y. Lian, S.T. Lee, Z.H. Kang, Carbon 49 (2011) 605, http://dx.doi.org/10.1016/j.carbon.2010.10.004. 
[10] N. Gong, H. Wang, S. Li, Y. Deng, X. Chen, Ling. Ye, W. Gu, Langmuir 30 (2014) 10933, http://dx.doi.org/10.1021/la502705g.

[11] A.B. Bourlinos, A. Stassinopoulos, D. Anglos, R. Zboril, M. Karakassides, E.P. Giannelis, Small 4 (2008) 455, http://dx.doi.org/10.1002/smll.200700578.

${ }_{[12]}$ S. Do, W. Kwon, S. Rhee, J. Mater. Chem. C. 2 (2014) 4221, http://dx.doi.org/ 10.1039/c4tc00090k.

[13] J.A. Lopez-Sanchez, N. Dimitratos, C. Hammond, et al., Nat. Chem. 3 (2011) 551 , http://dx.doi.org/10.1038/nchem.1066.

[14] V. Amendola, M. Meneghetti, Phys. Chem. Chem. Phys. 11 (2009) 3805, http:// dx.doi.org/10.1039/B900654K.

[15] R. Intartaglia, G. Das, K. Bagga, A. Gopalakrishanan, A. Genovese, M. Piova, E. Fabrizio, R. Cingolani, A. Diaspro, F. Brandi, Phys. Chem. Chem. Phys. 15 (2013) 3075, http://dx.doi.org/10.1039/C2CP42656K.

[16] R. Intartaglia, K. Bagga, F. Brandi, G. Das, A. Genovese, E. Fabrizio, A. Diaspro, J. Phys. Chem. C 115 (2011) 5102, http://dx.doi.org/10.1021/jp109351t.

[17] S. Petersen, S. Barcikowski, Adv. Funct. Mater. 19 (2009) 1167, http:// dx.doi.org/10.1002/adfm.200801526.

[18] A. Al-Hamaoy et al., Appl. Surf. Sci. 302 (2014) 141, http://dx.doi.org/10.1016/ j.apsusc.2013.09.102.

[19] R. Matsutani, K. Inoue, N. Wadab, K. Kojima, Chem. Commun. 47 (2011) 5840 , http://dx.doi.org/10.1039/C1CC00102G.

[20] S. Yang, M. Kertesz, J. Phys. Chem. A 110 (2006) 9771, http://dx.doi.org/ 10.1021/jp062701.

[21] R. Matsutani, F. Ozaki, R. Yamamoto, T. Sanada, Y. Okada, K. Kojima, Carbon 47 (2009) 1659, http://dx.doi.org/10.1016/j.carbon.2009.02.026.

[22] A. Kamyshny, J. Steinke, S. Magdassi, Open Appl. Phys. J. 4 (2011) 19, http:// dx.doi.org/10.2174/1874183501104010019.

[23] A. Kamyshny, M. Ben-Moshe, S. Aviezer, S. Magdassi, Macromol. Rapid Commun. 26 (2005) 281, http://dx.doi.org/10.1002/marc.200400522.

[24] B.J. Park, B.O. Park, B.H. Ryu, Y.M. Choi, K.S. Kwon, H.J. Choi, J. Appl. Phys. 108 (2010) 102803, http://dx.doi.org/10.1063/1.3511682.

[25] M.J. Pelletier, R. Altkorn, Anal. Chem. 73 (2001) 1393, http://dx.doi.org/ 10.1021/ac001220y.

[26] J. Wang, C. Wang, S. Chen, Angew. Chem. Int. Ed. 51 (2012) 9297, http:// dx.doi.org/10.1002/anie.201204381.

[27] D. Pan, J. Zhang, Z. Li, M. Wu, Adv. Mater. 22 (2010) 734, http://dx.doi.org/ 10.1002/adma.200902825.

[28] B.J. Clark, T. Frost, M.A. Russell, vol. 4, Chapman \& Hall, London, New York, 1993.

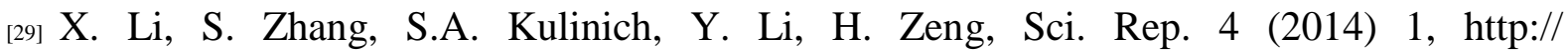
dx.doi.org/10.1038/srep04976.

[30] J. Zheng, R. Yang, L. Xie, J. Qu, Y. Liu, X. Li, Adv. Mater. 22 (2010) 1451, http:// dx.doi.org/10.1002/adma.200903147. 
[31] C.L. Sajti, R. Sattari, B.N. Chichkov, S. Barcikowski, J. Phys. Chem. C 114 (2010) 2421, http://dx.doi.org/10.1021/jp906960g.

[32] R. Intartaglia, K. Bagga, A. Genovese, A. Athanassiou, R. Cingolani, A. Diaspro, F. Brandi, Phys. Chem. Chem. Phys. 14 (2012) 15406, http://dx.doi.org/10.1039/ C2CP42195J.

[33] M. Tsuji, S. Kuboyama, T. Matsuzaki, T. Tsuji, Carbon 41 (2003) 2141, http:// dx.doi.org/10.1016/S0008-6223(03)00241-0.

[34] S. Shin, S. Park, Bull. Korean Chem. Soc. 33 (2012) 597, http://dx.doi.org/ 10.5012/bkcs.2012.33.2.597.

[35] R.M. Yadav, P.S. Dobal, T. Shripathi, R.S. Katiyar, O.N. Srivastava, Nanoscale Res. Lett. 4 (2009) 197, http://dx.doi.org/10.1007/s11671-008-9225-2.

[36] A.C. Ferrari, J. Robertson, Phys. Rev. B. 63 (2001) 121405(R), http://dx.doi.org/ 10.1103/PhysRevB.63.121405.

[37] T.V. Richter, F. Stelzl, J. Schulz-Gericke, B. Kerscher, U. Würfel, M. Niggemann, S. Ludwigs, J. Mater. Chem. 20 (2010) 874, http://dx.doi.org/10.1039/ B916778C.

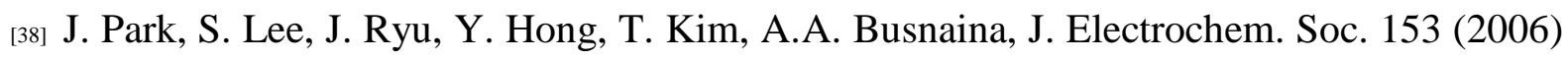
G811, http://dx.doi.org/10.1149/1.2214532.

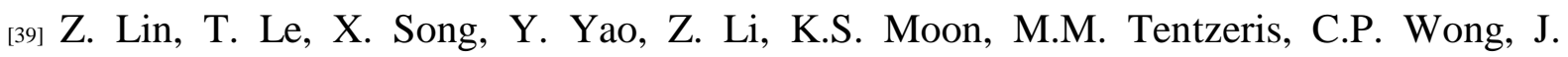
Electron. Packag. 135 (2013) 011007, http://dx.doi.org/10.1115/1.4023671.

${ }_{[40]}$ J. Tang, K.W. Kemp, S. Hoogland, K.S. Jeong, H. Liu, L. Levina, M. Furukawa, X. Wang, R. Debnath, D. Cha, K.W. Chou, A. Fischer, A. Amassian, J.B. Asbury, E.H. Sargentet, Nat. Mater. 10 (2011) 765, http://dx.doi.org/10.1038/nmat3118. 